\title{
Blendas PVC/NBR por Processamento Reativo I: Desenvolvimento do Processo de Vulcanização Dinâmica in situ
}

\author{
Fábio R. Passador, Luiz A. Pessan \\ Departamento de Engenharia de Materiais, UFSCar \\ Antonio Rodolfo Jr.
Braskem S/A
}

Resumo: Vulcanização dinâmica é o processo de vulcanização de um elastômero durante a mistura no estado fundido com um termoplástico, que resulta em uma classe de materiais denominada termoplásticos vulcanizados. Neste trabalho, um novo tipo de termoplástico vulcanizado foi obtido por vulcanização dinâmica in situ da blenda PVC/NBR, utilizando-se um sistema de cura a base de enxofre (S) e combinação dos aceleradores 2,2-ditiomercaptobenzotiazol (MBTS) e dissulfeto de tetrametiltiuram (TMTD). As blendas PVC/NBR (90/10, 80/20 e 70/30\% em massa) foram processadas em um reômetro de torque Haake (Rheomix 600) a $160{ }^{\circ} \mathrm{C}$ com rotação de $60 \mathrm{rpm}$. As blendas obtidas por processamento reativo foram caracterizadas por calorimetria diferencial de varredura (DSC) para determinação do grau de cura. Observou-se aumento no grau de cura das blendas com o tempo de mistura sendo o sistema de cura considerado eficiente.

Palavras-chave: Vulcanização dinâmica, poli (cloreto de vinila), borracha nitrílica, blenda PVC/NBR.

\section{PVC/NBR Blends by Reactive Processing I: In situ Dynamic Vulcanization Process}

\begin{abstract}
Dynamic vulcanization is a process of vulcanization of an elastomer during melt mixing with a thermoplastic wich results in material called thermoplastic vulcanizates or TPVs. In this study, a new kind of TPV was obtained by in situ dynamic curing of poly(vinyl chloride) (PVC)/nitrile rubber (NBR) blends. The crosslinking of PVC/NBR blends was accomplished using sulphur (S)/tetramethylthiuram disulphide (TMTD) and mercaptobenzthiazyl disulphide (MBTS) curative system during the reactive processing. The blends of PVC/NBR at the ratio of 90/10; 80/20 and 70/30 wt. (\%) were melt mixed using a Haake Rheomix 600 at $160{ }^{\circ} \mathrm{C}$ and rotor speed of $60 \mathrm{rpm}$. The curing behavior of NBR was investigated by a Monsanto Rheometer and the degree of cure was calculated using differential scanning calorimetry (DSC) for different mixing times. It was observed that the degree of cure increases with the mixing time and the crosslinking system used in this work was considered efficient.
\end{abstract}

Keywords: Dynamic vulcanization, poly (vinyl choride), nitrile rubber, reactive processing, PVC/NBR blends.

\section{Introdução}

Vulcanização é a conversão da borracha através de um processo químico de formação de ligações cruzadas, ou seja, um processo onde as cadeias moleculares, até então independentes, são unidas através de ligações químicas primárias formando reticulados, que levam a formação de uma rede tridimensional no material. Essa organização estrutural permite manter ou incrementar as propriedades elásticas e reduzir o comportamento plástico do material. $\mathrm{O}$ elastômero se torna insolúvel e mais resistente fisicamente num intervalo de temperatura maior que o da borracha não vulcanizada $^{[1-4]}$. O processo de vulcanização estática, utilizada comercialmente desde a época de Charles Goodyear, requer a adição de calor e de agente de cura em determinadas temperaturas $\left(130\right.$ a $\left.180{ }^{\circ} \mathrm{C}\right)$ por um tempo específico para formar as ligações cruzadas entre as macromoléculas dos elastômeros durante processos de transformação como moldagem por compressão, por exemplo ${ }^{[5]}$.

Vulcanização dinâmica é um processo de vulcanização de um elastômero durante a mistura no estado fundido com um termoplástico, que resulta em uma classe de materiais denominada termoplásticos vulcanizados, os quais apresentam as propriedades da borracha vulcanizada, porém pode ser processada como um termoplástico convencional ${ }^{[3,5]}$. Um grande número de elastômeros e termoplásticos são combinados para produzir tais termoplásticos por vulcanização dinâmica, incluindo as blendas NBR/Nylon, PP/EPDM e $\mathrm{PVC} / \mathrm{NBR}^{[4,5]}$.

O desenvolvimento de blendas vulcanizadas dinamicamente tem despertado grande interesse de pesquisadores, que buscam novos métodos de obtenção de blendas com propriedades específicas a cada aplicação. Zhu et al ${ }^{[6,7]}$ desenvolveram a blenda PVC/SBR, compatibilizada e vulca-

Autor para correspondência: Fábio Roberto Passador, Departamento de Engenharia de Materiais, UFSCar, Via Washington Luís, km 235, Caixa Postal 676, CEP: 13565-905,São Carlos, SP, Brasil. E-mail: fpassador@polvo.ufscar.br 
nizada dinamicamente, utilizando a borracha nitrílica para reduzir a tensão interfacial entre as fases, além da utilização de enxofre como agente de cura. A presença da borracha nitrílica induziu a vulcanização in situ na SBR e as blendas obtidas apresentam menor custo. Parnell e $\mathrm{Min}^{[8]}$ desenvolveram o processo de obtenção da blenda reativa in situ de PU com PVC, através da mistura de PVC com monômeros miscíveis ou oligômeros de TPU, os quais foram polimerizados posteriormente. Nessas blendas foi utilizado a adição de borracha nitrílica como agente compatibilizante, uma vez que NBR possui grande afinidade com o PVC, devido ao caráter polar da acrilonitrila.

Blendas de borracha nitrílica (NBR) e poli (cloreto de vinila) (PVC) são de grande interesse comercial. As borrachas nitrílicas são um dos principais modificadores em compostos de PVC, atuando como plastificantes permanentes, e conferindo melhoria na resistência ao ozônio e resistência química a matriz de PVC, enquanto que o PVC melhora as propriedades de abrasão, rasgamento e tração da $\mathrm{NBR}^{[9-11]}$. A formação de ligação cruzada in situ foi investigada por alguns pesquisadores. Manoj et al ${ }^{[12,13]}$ estudaram a vulcanização in situ de blendas PVC/NBR baseado na ausência de estabilizante térmico e na hidrólise dos grupos ciano da borracha nitrílica, no entanto as blendas foram obtidas por solução e as propriedades mecânicas obtidas são inferiores às da blenda PVC/NBR convencional. Gosh et $\mathrm{a}^{\left[{ }^{[14]}\right.}$ desenvolveram um sistema que promoveu vulcanização in situ da blenda PVC/NBR utilizando o sistema ETU (etileno tiouréia) e enxofre, o qual promoveu a formação de ligações cruzadas tanto no PVC quanto na NBR. A partir dos estudos de Mori e Nakamura, que utilizaram a modificação do PVC com NBR através da incorporação de aditivos funcionais, como ditiol triazina, na preparação da blenda, Oravec et a ${ }^{[15]}$ desenvolveram um sistema de cura para controlar as ligações interfaciais entre PVC e NBR através do uso de sais de amônio de tiol triazina, o qual se mostrou eficiente para a vulcanização in situ de blendas PVC/NBR. Em todos esses trabalhos foram utilizadas situações estáticas de vulcanização.

A indústria de borracha normalmente utiliza processos de vulcanização empregando sistemas de vulcanização à base de enxofre. De modo geral, a presença de dupla ligação na unidade butadiênica da borracha nitrílica facilita a vulcanização com enxofre, mas também a torna susceptível à oxidação e ataque por ozônio ${ }^{[1,4]}$.

Em um sistema de cura convencional utiliza-se uma combinação de aceleradores, ativadores e agente de cura. Os agentes de vulcanização são produtos químicos incorporados que provocam as ligações cruzadas entre as cadeias reagindo com o hidrogênio alílico do dieno, quando o composto é aquecido a uma temperatura apropriada. A combinação de agentes de vulcanização (aceleradores e ativadores) aumenta a taxa de vulcanização no sistema. Os aceleradores são componentes adicionados em pequenas quantidades com um agente de vulcanização para controlar o tempo e/ou temperatura necessária para a vulcanização. Os aceleradores reduzem o tempo de vulcanização através do aumento da velocidade da reação entre o enxofre e a borracha. As classes de aceleradores mais importantes incluem as sulfenamidas, mercaptobenzotiazóis, tiurans e aminas. As formulações de borracha podem conter um ou a combinação de dois tipos de aceleradores. Normalmente utilizam-se aceleradores da classe dos benzotiazóis combinados com aceleradores da classe dos tiurans ou aminas em pequenas quantidades. Os ativadores dos aceleradores são substâncias adicionadas em pequenas proporções que aumentam a ação efetiva dos aceleradores, sendo o mais comum o óxido de zinco e o ácido esteárico. Os sistemas de ativação aumentam a eficiência da reação de vulcanização, ativando o enxofre presente ti-4,16,17] $^{[}$

Embora a blenda PVC/NBR já tenha sido estudada por alguns pesquisadores, ainda há falta de informação sobre o processo de vulcanização dinâmica in situ desta blenda.

A proposta desse trabalho foi obter as blendas PVC/NBR nas proporções de 90/10, 80/20 e 70/30\% massa através de processamento reativo em reômetro de torque e promover a formação de ligações cruzadas in situ a NBR, utilizando sistemas de vulcanização à base de enxofre e combinação de aceleradores (2,2-ditiomercaptobenzotiazol (MBTS) e dissulfeto de tetrametiltiuram (TMTD)). $O$ grau de cura em cada etapa da mistura foi calculado por Calorimetria Exploratória Diferencial (DSC).

\section{Experimental}

\section{Materiais}

Foram utilizados neste estudo o poli (cloreto de vinila) (PVC) com valor $\mathrm{K}=71 \pm 1$, cedido pela Braskem S.A.; o dioctil ftalato (DOP), fornecido pela Scandiflex e o estabilizante térmico a base de $\mathrm{Ba} / \mathrm{Zn}$ fornecido pela Inbra Indústrias Químicas Ltda.

A borracha Nitrílica (NBR) com viscosidade Mooney $\left(\mathrm{MML}_{1+4} @ 100^{\circ} \mathrm{C}\right)$ igual a 48 e razão acrilonitrila/butadieno igual a 33/67\% em massa utilizada foi cedida pela Petroflex Indústria e Comércio S.A.

Os materiais óxido de zinco, ácido esteárico, 2,2-ditiomercaptobenzotiazol (MBTS), dissulfeto de tetrametiltiuram (TMTD), enxofre e antioxidante fenólico todos de grau comercial, foram utilizados como recebidos.

\section{Preparação dos compostos}

O composto de PVC foi obtido pela adição de 100 pcr de resina de PVC, 60 pcr de DOP e 3 pcr de estabilizante térmico em um misturador Mecanoplast ML- 9 , a $120{ }^{\circ} \mathrm{C}$.

A borracha nitrílica pré-ativada foi obtida utilizando o mesmo misturador Mecanoplast ML-9 a $70{ }^{\circ} \mathrm{C}$, sendo que primeiramente adicionou-se a NBR que foi misturada por 3 minutos e em seguida, a cada 2 minutos, foram adicionados $1,5 \mathrm{pcr}$ de óxido de zinco e 5 pcr ácido esteárico, 2 pcr de TMTD e 1 pcr de MBTS, e 2 pcr de enxofre, respectivamente.

\section{Determinação dos parâmetros de vulcanização}

A borracha nitrílica foi analisada em reômetro de disco oscilatório a $160^{\circ} \mathrm{C}$ com arco de $1^{\circ}$, segundo a norma ASTM 
D-2084. A partir da curva de comportamento reológico obtida, foram determinados os valores do torque máximo $\left(\mathrm{M}_{\mathrm{H}}\right)$, torque mínimo $\left(\mathrm{M}_{\mathrm{L}}\right)$, tempo de pré-cura $\left(\mathrm{t}_{\mathrm{S}} 1\right)$ e tempo ótimo de cura $\left(t_{90}\right)$.

\section{Preparação das blendas}

As blendas PVC/NBR nas proporções de 90/10; 80/20; $70 / 30 \%$ em massa foram obtidas in situ através da mistura em reômetro de torque Haake, modelo Rheomix 600, equipado com rotores do tipo "cam", do composto de PVC e da borracha nitrílica pré-ativada. A blenda foi processada a $160{ }^{\circ} \mathrm{C}$, com rotação de $60 \mathrm{rpm}$, variando-se o tempo de mistura. Foram retiradas amostras em tempos de mistura pré-determinados e imersas em nitrogênio líquido para congelamento do sistema e bloqueio da reação e posterior averiguação do grau de cura em cada etapa de mistura.

Sob as mesmas condições de processamento, foram preparadas blendas convencionais PVC/NBR nas proporções de 90/10; 80/20; 70/30\% em massa através da mistura em reômetro de torque Haake do composto de PVC e da borracha nitrílica com adição de 0,3 pcr de antioxidante fenólico.

\section{Análise térmica por DSC}

A análise térmica foi feita por Calorimetria Exploratória Diferencial (DSC) para averiguar a miscibilidade da blenda obtida através da comparação da Temperatura de Transição Vítrea $\left(\mathrm{T}_{\mathrm{g}}\right.$ ) do PVC, da NBR, das blendas PVC/NBR obtidas através de processamento reativo e das blendas convencionais. Para as análises, utilizou-se o aparelho da TA QS100, sendo que a faixa de temperatura estudada foi de -50 até $125{ }^{\circ} \mathrm{C}$, com taxa de aquecimento de $20{ }^{\circ} \mathrm{C} /$ minuto.

\section{Determinação do grau de cura}

O grau de cura foi avaliado por análises de Calorimetria Exploratória Diferencial (DSC), determinando-se a entalpia de cura total, ou seja, da amostra não-curada, e da cura residual da amostra parcialmente curada, calculada pela Equação 1, para as blendas PVC/NBR obtidas por processamento reativo.

$$
\text { Grau de cura }(\%)=\left[1-\frac{\Delta \mathrm{H}_{\text {cura residual }}}{\Delta \mathrm{H}_{\text {cura total }}}\right] \cdot 100
$$

Para as análises, utilizou-se o aparelho da TA QS100, sendo a faixa de temperatura estudada de $-50{ }^{\circ} \mathrm{C}$ até $320^{\circ} \mathrm{C}$, com taxa de aquecimento de $20{ }^{\circ} \mathrm{C} / \mathrm{min}$. Amostras foram preparadas em reômetro Haake e retiradas em intervalos de 30 segundos de mistura e imersas em nitrogênio líquido para análises por DSC.

\section{Resultados e Discussão}

\section{Parâmetros de vulcanização}

Os parâmetros de vulcanização obtidos são apresentados na Tabela 1. Para o sistema de cura utilizado baseado na mistura de aceleradores (MBTS e TMTD) foi possível obter
Tabela 1. Parâmetros de vulcanização da NBR para o sistema utilizado neste trabalho.

\begin{tabular}{cccc}
\hline \multicolumn{4}{c}{ Parâmetros de vulcanização } \\
\hline $\mathbf{M}_{\mathbf{L}}{ }^{\mathbf{a}}(\mathbf{N} . \mathbf{m})$ & $\mathbf{M}_{\mathbf{H}}{ }^{\mathbf{b}}(\mathbf{N} . \mathbf{m})$ & $\mathbf{t}_{\mathbf{S}} \mathbf{1}^{\mathbf{c}}(\mathbf{m i n})$ & $\mathbf{t}_{\mathbf{9 0}}{ }^{\mathbf{d}}(\mathbf{m i n})$ \\
\hline 17,0 & 53,8 & 2,0 & 3,5 \\
\hline
\end{tabular}

atorque mínimo; 'torque máximo; 'tempo de pré-cura; e dempo ótimo de cura.

valores de torque máximo maiores que os encontrados na literatura ${ }^{[17]}$. Foi obtido também um menor tempo ótimo de cura, porém utilizou-se neste trabalho uma maior quantidade de enxofre $(2 \mathrm{pcr}$ ) frente aos dados obtidos na literatura (1,3 pcr). O aumento da quantidade de enxofre promove um aumento na quantidade de ligações polissulfídicas e no grau de reticulação. Os valores de torque máximo são normalmente proporcionais à quantidade de ligações cruzadas formadas por volume de borracha, ou seja, à densidade de ligações cruzadas. O sistema utilizado, quantidade de acelerador maior que a quantidade de enxofre, é classificado como um sistema eficiente tendo como principal característica a formação de ligações mono e dissulfídicas em grande quantidade.

\section{Análise térmica}

A Figura 1 apresenta os termogramas do PVC, da NBR, das blendas PVC/NBR nas proporções de 90/10, 80/20 e $70 / 30 \%$ em massa vulcanizadas in situ e das blendas convencionais PVC/NBR nas proporções de 90/10, 80/20 e 70/30\% em massa, assim como os valores das $\mathrm{Tg}$ de cada componente e das blendas.

A miscibilidade ou grau de interação corresponde ao nível de mistura molecular entre os dois polímeros ou fases constituintes do sistema ${ }^{[18]}$. O estado de mistura do sistema PVC/ NBR está diretamente relacionado ao teor de acrilonitrila da borracha nitrílica. Segundo a literatura ${ }^{[19-21]}$, verifica-se que o grau de miscibilidade aumenta com o teor de acrilonitrila na NBR até um teor ótimo a partir da qual se observa o comprometimento das propriedades mecânicas, gerando blendas

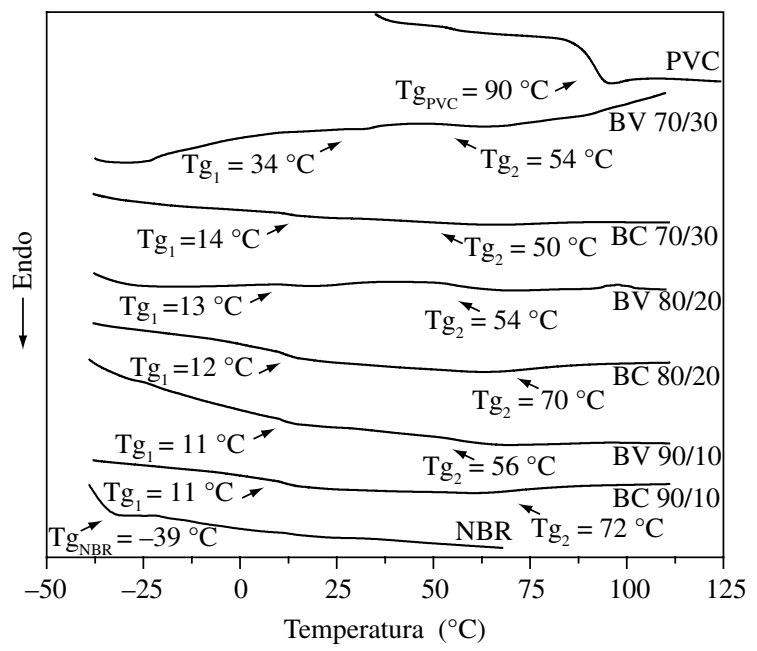

Figura 1. Termogramas do PVC, da NBR, das blendas PVC/NBR vulcanizadas in situ (BV) e das blendas convencionais PVC/NBR (BC). 
com morfologia de fases aglomeradas e heterogêneas. Em um teor de $33 \%$ de acrilonitrila da NBR observou-se um aumento no grau de miscibilidade da blenda PVC/NBR, porém a miscibilidade está também relacionada com o teor de PVC e NBR na composição.

Todas as blendas estudadas apresentaram dois valores de $\mathrm{Tg}$, sendo intermediárias entre a Tg do PVC $\left(90{ }^{\circ} \mathrm{C}\right)$ e da NBR $\left(-39{ }^{\circ} \mathrm{C}\right)$. Com relação à variação dos teores de NBR incorporados no PVC, pode-se observar pela análise térmica que os sistemas são imiscíveis, ou seja, houve a formação de mais de uma fase, notadamente pelo surgimento de dois valores de temperatura de transição vítrea. Verificou-se também que houve deslocamentos nos valores da $\mathrm{Tg}$, tanto do PVC quanto da NBR. Quanto maior o teor de NBR na blenda, mais próximos são os valores de $\mathrm{Tg}$, ou seja, o aumento da quantidade de acrilonitrila na composição da blenda aumenta o grau de interação e/ou miscibilidade parcial.

Para a blenda PVC/NBR (70/30) vulcanizada in situ estudada observou-se dois valores de $\mathrm{Tg}\left(34\right.$ e $\left.54^{\circ} \mathrm{C}\right)$, os valores obtidos estão mais próximos do que as demais blendas estudadas, porém o sistema também pode ser considerado imiscível. Já para a blenda PVC/NBR (70/30) convencional observou-se que os valores da $\mathrm{Tg}\left(14\right.$ e $\left.50{ }^{\circ} \mathrm{C}\right)$ estão se aproximando porém em menor intensidade. Segundo a literatura $^{[18-20]}$ o sistema PVC/NBR (com teor de 33\% de acrilonitrila) será miscível para quantidades de borracha nitrílica superiores a $30 \%$ na composição da blenda.

Em todos os sistemas estudados observou-se que as blendas vulcanizadas in situ apresentaram menor distância entre os valores de $\mathrm{Tg}$, sendo um indicativo de que a formação de ligações cruzadas nestes sistemas auxilia na obtenção de blendas com maior grau de miscibilidade em comparação as blendas convencionais.

\section{Determinação do grau de cura}

O grau de cura pode ser calculado pela Equação 1, a partir da entalpia de cura total, obtida por DSC. Primeiramente, foram calculadas as variações de entalpia das amostras nãocuradas $\left(\Delta \mathrm{H}_{\text {cura total }}\right)$. Os valores obtidos foram 1,86, 1,23 e 2,10 J.g ${ }^{-1}$, para as blendas PVC/NBR 90/10, 80/20 e 70/30, respectivamente. Posteriormente, foram realizados ensaios de DSC com as amostras retiradas do reômetro de torque em intervalos de 30 segundos e os valores da entalpia de cura residual $\left(\Delta \mathrm{H}_{\text {cura residual }}\right)$ foram obtidos. A Figura 2 apresenta a relação entre o grau de cura e o tempo de mistura das blendas estudadas. A Tabela 2 apresenta os tempos de mistura, os valores de $\Delta \mathrm{H}_{\text {cura residual }}(\Delta \mathrm{Hc})$ e grau de cura $(\mathrm{GC}$, em $\%)$ das blendas PVC/ NBR (90/10, 80/20 e 70/30\% em massa) vulcanizadas in situ.

Observou-se que com o decorrer do tempo ocorre vulcanização dinâmica in situ da borracha nitrílica em todas as blendas estudadas, comprovada pelo aumento no grau de cura do sistema. Para tempos maiores de mistura foram obtidos maiores graus de cura, ou seja, houve tempo de mistura suficiente para ocorrer maior nível de reação de formação de ligações cruzadas.

Para a blenda PVC/NBR (90/10) com tempo de mistura de 660s observou-se que grande parte da borracha nitrílica reagiu, formando ligações cruzadas e obtendo grau de cura de $85,5 \%$, enquanto que para a blenda PVC/NBR (70/30) foi possível obter $92,4 \%$ de cura com tempo de mistura de 210 segundos.

Com o aumento da quantidade de NBR na blenda nota-se que a vulcanização ocorre de forma mais acentuada em menores

Tabela 2. Valores de tempo de mistura, $\Delta \mathrm{H}_{\text {cura residual }}(\Delta \mathrm{Hc})$ e grau de cura $(\mathrm{GC})$ das blendas PVC/NBR nas proporções de $90 / 10,80 / 20$ e $70 / 30 \%$ em massa.

\begin{tabular}{|c|c|c|c|c|c|c|}
\hline \multirow[t]{2}{*}{ Tempo de mistura (s) } & \multicolumn{2}{|c|}{ Blenda PVC/NBR (90/10) } & \multicolumn{2}{|c|}{ Blenda PVC/NBR (80/20) } & \multicolumn{2}{|c|}{ Blenda PVC/NBR (70/30) } \\
\hline & $\Delta \mathbf{H c}^{\mathrm{a}}(\mathbf{J} / \mathbf{g})$ & $\mathrm{GC}^{\mathbf{b}}(\%)$ & $\Delta \mathbf{H c}(\mathbf{J} / \mathbf{g})$ & GC (\%) & $\Delta \mathbf{H c}(\mathbf{J} / \mathbf{g})$ & GC $(\%)$ \\
\hline 30 & 1,67 & 10,22 & 1,17 & 4,89 & 1,90 & 9,54 \\
\hline 60 & 1,29 & 30,65 & 0,90 & 26,83 & 1,86 & 11,43 \\
\hline 90 & 1,16 & 37,63 & 0,80 & 34,96 & 1,74 & 17,14 \\
\hline 120 & 0,90 & 51,61 & 0,70 & 43,09 & 1,60 & 23,81 \\
\hline 150 & 0,84 & 54,84 & 0,69 & 43,90 & 1,50 & 28,57 \\
\hline 180 & 0,83 & 55,38 & 0,68 & 44,72 & 1,20 & 42,86 \\
\hline 210 & 0,81 & 56,45 & 0,66 & 46,34 & 0,16 & 92,38 \\
\hline 240 & 0,80 & 56,99 & 0,66 & 46,34 & - & - \\
\hline 270 & 0,72 & 61,29 & 0,66 & 46,34 & - & - \\
\hline 300 & 0,70 & 62,36 & 0,56 & 54,47 & - & - \\
\hline 330 & 0,71 & 61,83 & 0,49 & 60,16 & - & - \\
\hline 360 & 0,70 & 62,36 & 0,48 & 60,98 & - & - \\
\hline 390 & 0,67 & 63,98 & 0,40 & 67,48 & - & - \\
\hline 410 & 0,64 & 65,60 & 0,36 & 70,73 & - & - \\
\hline 450 & 0,62 & 66,66 & 0,30 & 75,61 & - & - \\
\hline 480 & 0,50 & 73,12 & 0,20 & 83,74 & - & - \\
\hline 510 & 0,47 & 74,73 & - & - & - & - \\
\hline 540 & 0,41 & 77,96 & - & - & - & - \\
\hline 570 & 0,40 & 78,49 & - & - & - & - \\
\hline 600 & 0,33 & 82,26 & - & - & - & - \\
\hline 630 & 0,32 & 82,80 & - & - & - & - \\
\hline 660 & 0,27 & 85,48 & - & - & - & - \\
\hline
\end{tabular}

${ }^{\mathrm{a}} \Delta \mathrm{H}$

grau de cura. 


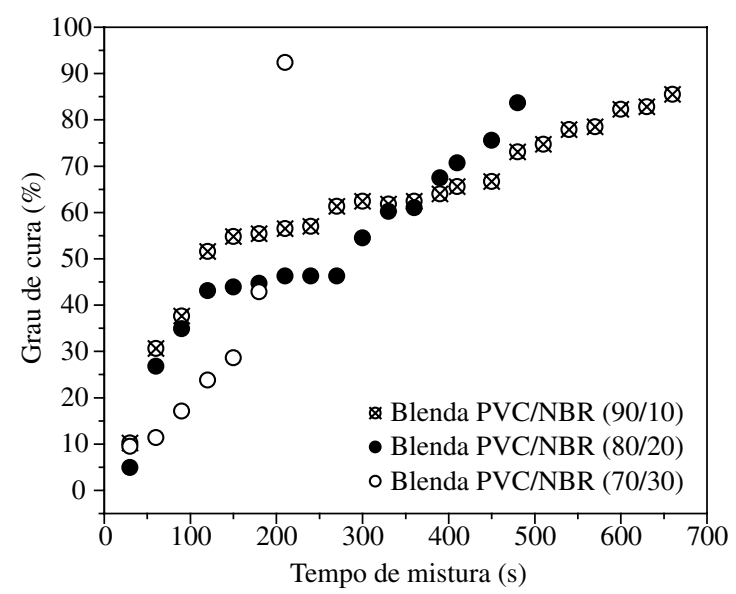

Figura 2. Relação entre grau de cura $(\%)$ e tempo de mistura das blendas PVC/NBR nas proporções de 90/10, 80/20 e 70/30\% em massa.

tempos de mistura, notadamente pelo aumento das quantidades de enxofre e aceleradores na blenda. O sistema de cura utilizado é eficiente, ou seja, a razão entre aceleradores e enxofre de 1,5 é adequada para a cura desejada no sistema em estudo.

Os dados obtidos por reometria de disco oscilatório mostram que o tempo ótimo de cura para a borracha nitrílica é de aproximadamente 3,5 minutos, para a blenda PVC/NBR o tempo de cura é aumentado devido à presença da fase PVC e também ao menor cisalhamento observado no reômetro de torque em comparação ao reômetro de disco oscilatório.

Segundo a literatura ${ }^{[13-15]}$ foram obtidas blendas in situ com teor de $50 \%$ de NBR, porém com vulcanização estática. Para os sistemas estudados, com menores quantidades de borracha nitrílica, foi possível obter a formação de ligações cruzadas in situ da blenda através do processamento reativo, com um máximo de $92,4 \%$ de grau de cura num tempo de 210 segundos para a blenda PVC/NBR (70/30).

\section{Conclusões}

Foi possível obter as blendas PVC/NBR nas proporções de 90/10, 80/20 e 70/30\% em massa através de processamento reativo com a formação de ligações cruzadas in situ.

O sistema de cura utilizado, quantidade de acelerador maior que a quantidade de enxofre, é classificado como um sistema eficiente tendo como principal característica a formação de ligações mono e dissulfídicas em grande quantidade.

Através da análise térmica, observou-se a presença de duas temperaturas de transição vítreas ( $\mathrm{Tg}$ ) em todas as blendas estudadas, sendo um indicativo da imiscibilidade destes sistemas, sendo que a miscibilidade de blendas PVC/NBR está relacionada ao teor de NBR na composição e ao teor de acrilonitrila da borracha nitrílica. Com o aumento do teor de NBR ocorreu uma aproximação dos valores de Tg, o que indica um aumento no grau de miscibilidade e/ou interação entre as fases, sendo esta aproximação mais acentuada para as blendas obtidas por processamento reativo.
Para maiores tempos de mistura em reômetro de torque observou-se que ocorre a vulcanização dinâmica in situ das blendas pelo aumento do grau de cura. Para o sistema PVC/ NBR (90/10) foi possível obter um máximo grau de cura de $85,5 \%$ num tempo de 660 segundos, enquanto que o sistema PVC/NBR (70/30) para um tempo de mistura de 210 segundos obteve-se um máximo de grau de cura de $92,4 \%$.

\section{Agradecimentos}

Os autores agradecem a Capes pelo apoio financeiro e a Braskem S.A. através do programa NEO PVC (Núcleo de Estudos Orientados do PVC).

\section{Referências Bibliográficas}

1. Browmick, A. K.; Hall, M. M. \& Benarey, H. A. - "Rubber products manufacturing technology", Marcel Dekker Inc, New York (1997).

2. Hills, D. A. - "Heat transfer and vulcanisation of rubber", Applied Science Publishers Ltd., Londres (1971).

3. Coran, A. Y. in: Handbook of elastomers - new developments and technology, Stephens H. L., (ed.), Dekker Inc, New York (1988).

4. Akiba, M. \& Hashim, A. S. - Prog. Polym. Sci., 22, p.475 (1997).

5. Walker B. M. \& Rader C. P. - "Handbook of thermoplastic elastomers", Van Nostrand Reinhold, New York (1988).

6. Zhu, S. H.; Chan, C. M. \& Zhang, Y. X. - J. Appl. Polym. Sci., 58, p.621 (1995).

7. Zhu, S. H. \& Chan, C. M. - Polym., 39, p.7023 (1998).

8. Parnell, S. \& Min, K. - Polym. Eng. Sci., 45, p.876 (2005).

9. Paul, D. R. \& Newman, S. - "Polymers blends", vol.1, Academic Press, New York (1978).

10. Passador, F. R.; Pessan, L. A. \& Rodolfo, Jr A. - Pol.: Ciênc. Tecnol., 16, p.174 (2006).

11. Shen, F.; Li, H.; Wu, C. - J. Polym. Sci., Part B: Polym. Phys., 44, p.378 (2006).

12. Manoj, N. R.; De, P. P.; De, S. K. - J. Appl. Polym. Sci., 49, p.133 (1993).

13. Manoj, N. R.; De, P. P. - Polym., 39, p.733 (1998).

14. Gosh, P.; Sem, A. K. \& Ray, P. - Polym., 33, p.744 (1992).

15. Oravec J.; Oishi Y.; Hirahara H. \& Mori K. - Polym. Inter., 32, p.303 (1993).

16. Morton, M. - "Rubber Technology", Robert E. Krieger Publishing Company, Florida (1981).

17. Oliveira, M. G. \& Soares, B. G. - Pol.: Ciênc.Tecnol., 12, p.11 (2002).

18. Paul, D. R. \& Newman, S. - "Polymer Blends", Academic Press Inc, New York (1978).

19. Wang, Q.; Zhang, X.; Liu, S.; Gui, H. \& Lai J. - Polym., 46, p.10614 (2005).

20. Sen, A.; Mukherjee, G. S. - Polym., 34, p.2386 (1993).

21. Huang J. C. - J. Appl. Polym. Sci., 89, p.1242 (2003). 